\title{
Application of Nanometer Antimony Trioxide Modified by Dioctyl Phthalate in Polyvinyl Chloride Flame Retardant Materials
}

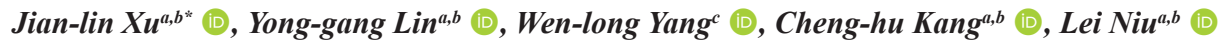 \\ ${ }^{a}$ Lanzhou University of Technology, College of Materials Science \& Engineering, Lanzhou 730050, China \\ ${ }^{b}$ Lanzhou University of Technology, State Key Laboratory of Advanced Processing and Recycling of \\ Non-ferrous Metals, Lanzhou 730050, China \\ ${ }^{c}$ Hexi University, School of Physical and Mechanical Engineering, Zhangye 734000, China
}

Received: July 16, 2020; Revised: October 29, 2020; Accepted: December 14, 2020

In order to improve the compatibility and dispersion of antimony trioxide nanoparticles (nano$\mathrm{Sb}_{2} \mathrm{O}_{3}$ ) in polyvinyl chloride (PVC) and improve the comprehensive properties of PVC, a novel type of nano- $\mathrm{Sb}_{2} \mathrm{O}_{3} / \mathrm{DOP} / \mathrm{PVC}$ composites was prepared by using nano- $\mathrm{Sb}_{2} \mathrm{O}_{3}$ modified by dioctyl phthalate (DOP) as flame retardant and the mechanical properties and flame-retardant properties of the composites were studied. The results indicated that nano- $\mathrm{Sb}_{2} \mathrm{O}_{3}$ particles modified by appropriate DOP could improve the flame retardancy and tensile strength of PVC matrix composites due to good dispersibility and interface compatibility of nano- $\mathrm{Sb}_{2} \mathrm{O}_{3}$ in PVC matrix. The PVC matrix composites containing $2 \mathrm{wt} \%$ nano- $\mathrm{Sb}_{2} \mathrm{O}_{3}$ particles modified by DOP with $5 \mathrm{wt} \%$ of usage had excellent flame retardancy, which LOI was $29.8 \%$ and its UL94 grade was V-0 level. And the heat release rate,smoke production rate, $\mathrm{CO}$ content and $\mathrm{CO}_{2}$ content of the composites was significantly reduced. Meanwhile, the tensile strength and Young's modulus of the composites were 15.9 MPa and $2.1 \mathrm{GPa}$, respectively.

Keyword: polyvinyl chloride, antimony trioxide nanoparticles, dioctyl phthalate, composites, flame retardancy, mechanical properties.

\section{Introduction}

Polyvinyl chloride (PVC), as the earliest industrial resins, is one of the most common polymers. It is widely concerned due to its excellent mechanical properties, corrosion resistance, plasticity and insulating properties. According to the amount of plasticizer, there are three types of PVC, namely soft products, rigid products and semi-rigid products. As is known, $\mathrm{PVC}$ resin has good flame-retardant performance in itself with the range of limiting oxygen index (LOI) from $45 \%$ to $49 \%$. However, the LOI of PVC products is sometimes even lower than $20 \%$ due to the high content of plasticizer, which causes PVC products easy to burn ${ }^{1,2}$. Moreover, due to the poor thermal stability of PVC, thermal degradation can release some low molecular compounds such as $\mathrm{HCl}, \mathrm{CO}$ and benzene during combustion, resulting in a large amount of black smoke and corrosive gases in burning. It will cause secondary harm that the smoke will seriously affect people's lives and property and even pollute people's living environment ${ }^{3-5}$. Adding flame retardant into PVC is an effective way to solve the flammability of PVC products. The flame retardants for PVC mainly include inorganic flame retardants and organic flame retardants. Inorganic flame retardants occupy the main market with many advantages such as non-toxic gas released, environment-friendly, long effect duration and low $\operatorname{cost}^{6,7}$. Antimony trioxide nanoparticles $\left(\right.$ nano- $\left.\mathrm{Sb}_{2} \mathrm{O}_{3}\right)$ have been widely concerned because of good synergistic fire-retardant effect between nano- $\mathrm{Sb}_{2} \mathrm{O}_{3}$ and halogen flame retardants ${ }^{8,9}$. It is reasonable to use nano- $\mathrm{Sb}_{2} \mathrm{O}_{3}$ as flame retardant additive for PVC containing chlorine elements. Some research results

*e-mail address:ggdjlxu@sina.com show that nano- $\mathrm{Sb}_{2} \mathrm{O}_{3}$ has good flame-retardant effect on PVC and little effect on its mechanical properties ${ }^{1,10,11}$. However, due to the nanometer effect of nanoparticles, nanoparticles are easy to form agglomerates and lead to poor dispersion in the polymer, resulting in affecting the flame retardant and mechanical properties of the polymer. In other words, how to make the nanoparticles have good interfacial compatibility and dispersion in PVC is a key problem that affects the flame retardant and mechanical properties of $\mathrm{PVC}^{12}$. Therefore, it is necessary to modify nano- $\mathrm{Sb}_{2} \mathrm{O}_{3}$ to improve its compatibility with matrix material and its dispersion in polymer. If the surface of nano- $\mathrm{Sb}_{2} \mathrm{O}_{3}$ is modified by dioctyl phthalate (DOP), the modified nano- $\mathrm{Sb}_{2} \mathrm{O}_{3}$ can not only improve the interfacial compatibility between nano- $\mathrm{Sb}_{2} \mathrm{O}_{3}$ and $\mathrm{PVC}$ matrix, but also improve dispersion in $\mathrm{PVC}$, resulting in improve flame retardancy and mechanical properties of PVC. At present, our team has realized that the surface of nano- $\mathrm{Sb}_{2} \mathrm{O}_{3}$ was modified by DOP basing on mechanical ball milling technology ${ }^{13}$. In the paper, a novel type of nano- $\mathrm{Sb}_{2} \mathrm{O}_{3} / \mathrm{DOP} / \mathrm{PVC}$ composite material was prepared by using nano- $\mathrm{Sb}_{2} \mathrm{O}_{3}$ modified by $\mathrm{DOP}$ as flame retardant and the mechanical properties and flame-retardant properties of the composites were studied.

\section{Experimental}

\subsection{Materials}

The experimental PVC was obtained from Hefei Anbang Chemical Co., Ltd. of China. DOP was provided from Laiyang 
Shuangshuang Chemical Co., Ltd. of China. Nano- $\mathrm{Sb}_{2} \mathrm{O}_{3}$ was prepared by ball milling method and labeled as unmodified nano- $\mathrm{Sb}_{2} \mathrm{O}_{3}$, as reported in our study ${ }^{14}$.

\subsection{Preparation of nanocomposites}

Firstly, the nano- $\mathrm{Sb}_{2} \mathrm{O}_{3}$ were modified by a high energy ball milling (QM-3SP04, Nanjing Laibu Science and Technology Industry Co. Ltd., Jiangsu, China) with the different content of DOP, as reported in our study ${ }^{13}$ and the resulting nano- $\mathrm{Sb}_{2} \mathrm{O}_{3}$ was labeled as modified nano- $\mathrm{Sb}_{2} \mathrm{O}_{3}$. The usage of DOP is $3 \mathrm{wt} \%$ and $5 \mathrm{wt} \%$ and $7 \mathrm{wt} \%$ of the mass fraction of $\mathrm{Sb}_{2} \mathrm{O}_{3}$, respectively. These above modified nano- $\mathrm{Sb}_{2} \mathrm{O}_{3}$ were also labeled as nano- $\mathrm{Sb}_{2} \mathrm{O}_{3} @ 3 \mathrm{wt} \% \mathrm{DOP}$, nano- $\mathrm{Sb}_{2} \mathrm{O}_{3} @ 5 w t \%$ DOP and nano- $\mathrm{Sb}_{2} \mathrm{O}_{3} @ 7 w t \%$ DOP, respectively. The rotation speed was $400 \mathrm{r} / \mathrm{min}$ and the ball milling time was $6 \mathrm{~h}$ in the process. Secondly, the modified nano- $\mathrm{Sb}_{2} \mathrm{O}_{3}$ and the unmodified nano- $\mathrm{Sb}_{2} \mathrm{O}_{3}$ were added into PVC matrix and mixed by ball mill, respectively. The rotation speed was $400 \mathrm{r} / \mathrm{min}$. The process of turning 6 minutes and then stopping for 3 minutes was repeated 60 times. Thirdly, DOP with $33.3 \mathrm{wt} \%$ of mass fraction was added into the mixed materials, and then thoroughly stirred and dried. Finally, the test samples were obtained by melt blending and injection molding methods, in which the melt blending was completed by SJZS-10A twin-screw extruders (Wuhan Ruiming Machinery Manufacture Co., Ltd., China) and injection molding was completed by SZS-20 injection molding machine (Wuhan Ruiming Machinery Manufacture Co., Ltd., China). The compositions of experimental materials are listed in Table 1.

\subsection{Characterization}

The surface states of unmodified nano- $\mathrm{Sb}_{2} \mathrm{O}_{3}$ and modified nano- $\mathrm{Sb}_{2} \mathrm{O}_{3}$ were characterized by FTIR-650 Fourier Transform Infrared Spectrophotometer (FTIR, Tianjin Gangdong Technology Development Co., Ltd., China). The spectral range was from $4000 \mathrm{~cm}^{-1}$ to $400 \mathrm{~cm}^{-1}$ and the scanning speed was $4 \mathrm{~cm}^{-1}$. The testing samples were compressed into tablets by using SDY-30 electric powder tablet pressing machine (Tianjin Science and Technology High-tech Co., Ltd., China).

The thermogravimetric analysis (TGA) was characterized by TGA 4000 thermogravimetric analyzer (PerkinElmer Instruments Co., Ltd., USA) under nitrogen. The range of sample mass was $4 \sim 6 \mathrm{mg}$. The samples were heated from room temperature to $700{ }^{\circ} \mathrm{C}$ at a linear heating rate of $10{ }^{\circ} \mathrm{C} / \mathrm{min}$ by using an open alumina crucible.

The fire behavior under forced-flaming conditions was assessed by using a CCT cone calorimeter (Mordis Combustion Technology Co., Ltd., China). The tests were

Table 1. Composition of experimental materials (mass fraction, wt $\%$ ).

\begin{tabular}{cccc}
\hline Samples & PVC & DOP & $\begin{array}{r}\text { Nano- } \mathrm{Sb}_{2} \mathrm{O}_{3} @ \text { Modifier and mass } \\
\text { ratio in nano- } \mathrm{Sb}_{2} \mathrm{O}_{3}\end{array}$ \\
\hline PVC0 & 66.7 & 33.3 & 0 \\
\hline PVC1 & 64.7 & 33.3 & $2 \mathrm{wt} \%$ nano- $\mathrm{Sb}_{2} \mathrm{O}_{3}$ \\
\hline PVC2 & 64.7 & 33.3 & $2 \mathrm{wt} \%$ nano- $\mathrm{Sb}_{2} \mathrm{O}_{3} @ 3 \mathrm{wt} \% \mathrm{DOP}$ \\
\hline PVC3 & 64.7 & 33.3 & $2 \mathrm{wt} \%$ nano- $\mathrm{Sb}_{2} \mathrm{O}_{3} @ 5 \mathrm{wt} \% \mathrm{DOP}$ \\
\hline PVC4 & 64.7 & 33.3 & $2 \mathrm{wt} \%$ nano- $\mathrm{Sb}_{2} \mathrm{O}_{3} @ 7 \mathrm{wt} \% \mathrm{DOP}$ \\
\hline
\end{tabular}

performed according to ISO 5660-1:2015 standard $^{15}$. The size of the test sample was $100 \times 100 \times 21 \mathrm{~mm}^{3}$ and the weight was $170 \pm 3 \mathrm{~g}$. The specimens were measured in aluminum foil and exposed horizontally to an external heat flux of $50 \mathrm{kw} / \mathrm{m}^{2}$ from the heating coils under well-ventilated conditions (air flow ratio of $24 \mathrm{~L} / \mathrm{s}$ ). The combustion residues were observed by scanning electron microscope (SEM, JSM-6700F, JEOL Ltd., Japan).

The limiting oxygen index (LOI) was analyzed by PX01-005 limited oxygen index tester (Suzhou Phinix Quality Inspection Instrument Co. Ltd. of China) according to GB/T2406.2-2009 ${ }^{16}$. The vertical burning test (UL94 grade) was performed by STD-94 vertical burning instruments (Shanghai Pan Standard Textile Testing Technology Co. Ltd., China) according to GB/T2408-2008. The size of the sample for the LOI test and UL94 test was $80 \mathrm{~mm} \times 10 \mathrm{~mm} \times 4 \mathrm{~mm}$.

The tensile tests of samples were carried out by HS-100KN universal mechanical tensile testing machine (Yangzhou Huahui Inspection Instrument Co., Ltd., China) with a crosshead speed of $20 \mathrm{~mm} / \mathrm{min}$ and the tensile strength and Young's modulus of the samples were recorded according to GB/T 1040.1-2006 standard. The resulting value was the average value of at least five samples.

\section{Results and Discussion}

\subsection{Surface adsorption state of nano- $\mathrm{Sb}_{2} \mathrm{O}_{3}$ particles}

Figure 1 shows the FTIR spectrums of modified nano$\mathrm{Sb}_{2} \mathrm{O}_{3}$ and unmodified nano- $\mathrm{Sb}_{2} \mathrm{O}_{3}$ particles, respectively. For unmodified nano- $\mathrm{Sb}_{2} \mathrm{O}_{3}$, the absorption peak at $3414 \mathrm{~cm}^{-1}$ belongs to the hydroxyl stretching vibration peak and the peak at $1637 \mathrm{~cm}^{-1}$ belongs to the hydroxyl bending vibration peak. The appearance of these two absorption peaks indicates that the surface of the nano- $\mathrm{Sb}_{2} \mathrm{O}_{3}$ contains hydroxyl groups. Due to the large specific surface area and high surface energy of nanoparticles, the surface of the nano- $\mathrm{Sb}_{2} \mathrm{O}_{3}$ can absorb some water in the air, resulting in a large number of hydroxyl groups on its surface. Compared with the unmodified nano- $\mathrm{Sb}_{2} \mathrm{O}_{3}$, the FTIR spectra of modified nano- $\mathrm{Sb}_{2} \mathrm{O}_{3}$ appears four new absorption peaks at

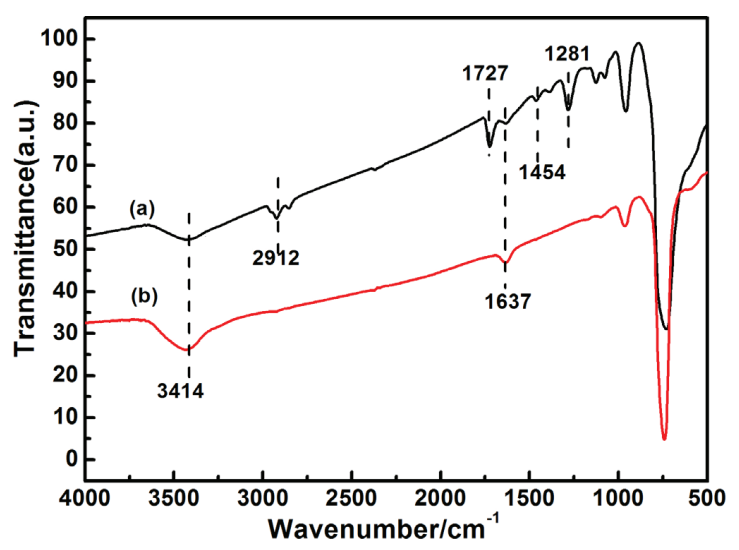

Figure 1. FTIR spectra of nano- $\mathrm{Sb}_{2} \mathrm{O}_{3}$ particles. (a) modified nano$\mathrm{Sb}_{2} \mathrm{O}_{3}$; (b) unmodified nano- $\mathrm{Sb}_{2} \mathrm{O}_{3}$. 
$2912 \mathrm{~cm}^{-1}, 1727 \mathrm{~cm}^{-1}, 1454 \mathrm{~cm}^{-1}$ and $1281 \mathrm{~cm}^{-1}$. The peak $2912 \mathrm{~cm}^{-1}$ is assigned to the asymmetric alkyl stretching vibration peak. The peak $1727 \mathrm{~cm}^{-1}$ is characteristic of the carbonyl absorption peak. The peaks at $1454 \mathrm{~cm}^{-1}$ and $1281 \mathrm{~cm}^{-1}$ are ascribed to benzene ring skeleton vibration absorption peak and ether bond absorption peak, respectively. Meanwhile, the peaks intensity of the hydroxyl stretching vibration peak and bending vibration peak are obviously weakened. The appearing of these new absorption peaks and the weakening of characteristic absorption peak intensity of hydroxyl group indicate that DOP is successfully absorbed onto the surface of nano- $\mathrm{Sb}_{2} \mathrm{O}_{3}$ and the adsorption capacity of hydroxyl group on the surface of the surface of nano$\mathrm{Sb}_{2} \mathrm{O}_{3}$ is decreased.

\subsection{Particle size analysis}

Figure 2 shows the particle size distribution of the experimental nano- $\mathrm{Sb}_{2} \mathrm{O}_{3}$. It can be seen from the figure that most of the particle size of the unmodified nano- $\mathrm{Sb}_{2} \mathrm{O}_{3}$ are distributed in the range of $100-500 \mathrm{~nm}$, while only a small part of the particle size distribution of unmodified nano$\mathrm{Sb}_{2} \mathrm{O}_{3}$ is in the range of $0-100 \mathrm{~nm}$. In the process of preparing $\mathrm{Sb}_{2} \mathrm{O}_{3}$ nanoparticles by using mechanical ball milling method, the agglomeration phenomenon of $\mathrm{Sb}_{2} \mathrm{O}_{3}$ particles becomes more serious with the refinement of the particles, resulting

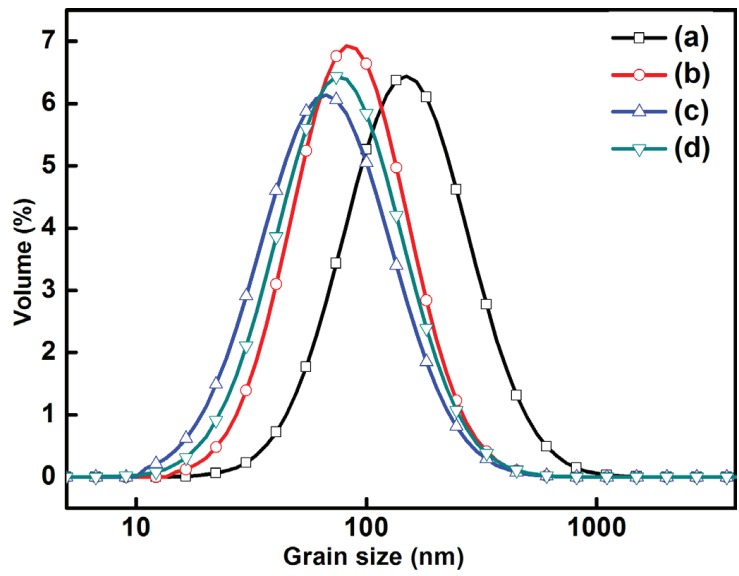

Figure 2. Particle size distribution of the experimental nano- $\mathrm{Sb}_{2} \mathrm{O}_{3}$. (a)unmodified nano- $\mathrm{Sb}_{2} \mathrm{O}_{3}$, (b) nano- $\mathrm{Sb}_{2} \mathrm{O}_{3} @ 3 \mathrm{wt} \% \mathrm{DOP}$, (c) nano$\mathrm{Sb}_{2} \mathrm{O}_{3} @ 5 \mathrm{wt} \% \mathrm{DOP},(\mathrm{d})$ nano- $\mathrm{Sb}_{2} \mathrm{O}_{3} @ 7 \mathrm{wt} \% \mathrm{DOP}$.

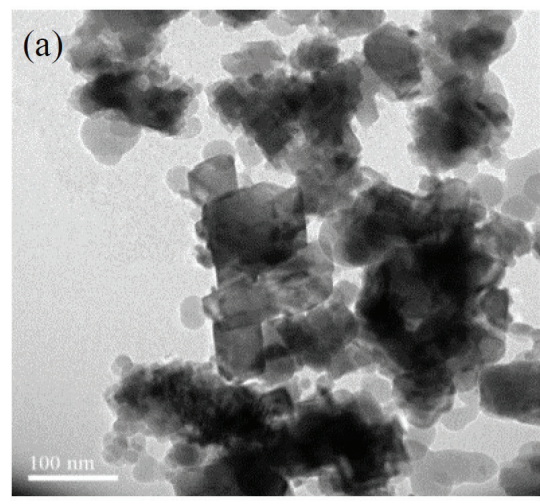

in the difficult to obtain the nanoparticles. The particle size of nano- $\mathrm{Sb}_{2} \mathrm{O}_{3}$ modified by DOP was significantly smaller than that of unmodified nanoparticles. When the amount of modifier DOP reaches $5.0 \mathrm{wt} \%$, the average particle size distribution of modified nano- $\mathrm{Sb}_{2} \mathrm{O}_{3}$ reaches the minimum and its particle size mainly distributes in the range of 90-160 $\mathrm{nm}$. Appropriate DOP can react with the unsaturated bond on the surface of nano- $\mathrm{Sb}_{2} \mathrm{O}_{3}$ to make it tend to be saturated, thus reducing the surface energy of nano- $\mathrm{Sb}_{2} \mathrm{O}_{3}$ and slowing down the agglomeration. When the amount of modified DOP is too high, the excessive DOP coating on the surface of nano- $\mathrm{Sb}_{2} \mathrm{O}_{3}$ will cause hydrogen bonding effect and Brownian motion effect, resulting in increasing of agglomeration of nano- $\mathrm{Sb}_{2} \mathrm{O}_{3}$.

Figure 3 shows TEM images of unmodified nano$\mathrm{Sb}_{2} \mathrm{O}_{3}$ and nano- $\mathrm{Sb}_{2} \mathrm{O}_{3} @ 5 \mathrm{wt} \%$ DOP particles. There is a serious agglomeration phenomenon in the TEM image of unmodified nano- $\mathrm{Sb}_{2} \mathrm{O}_{3}$. For nano- $\mathrm{Sb}_{2} \mathrm{O}_{3} @ 5 \mathrm{wt} \% \mathrm{DOP}$, the agglomeration of the nanoparticles is obviously weakened and shows better dispersion.

\subsection{Thermal decomposition behaviors}

Figure 4 shows the TGA and DTG curves of the experimental materials and Table 2 presents the corresponding thermal degradation parameters, including the decomposition temperature $\left(\mathrm{T}_{\mathrm{d}}\right)$ defined as the temperature at which $1 \mathrm{wt} \%$ mass loss of experimental materials occurs, the temperature of $10 \mathrm{wt} \%$ mass loss $\left(\mathrm{T}_{10}\right)$, the temperature of $50 \mathrm{wt} \%$ mass loss $\left(\mathrm{T}_{50}\right)$, the temperature with occurring of the maximum mass loss rate in the first decomposition stage $\left(\mathrm{T}_{\mathrm{P} 1}\right)$, the temperature with occurring of the maximum mass loss rate in the second decomposition stage $\left(\mathrm{T}_{\mathrm{p} 2}\right)$ and the char residue.

The thermal degradation of the experimental materials was completed in two steps. In the first stage $\left(230 \sim 450{ }^{\circ} \mathrm{C}\right)$, the mass loss caused by degradation of DOP and the removal of hydrogen chloride $(\mathrm{HCl})^{17,18} \cdot \mathrm{T}_{\mathrm{d}}$ of $\mathrm{PVC} 0$ is higher than that of the PVC matrix composites and $\mathrm{T}_{10}$ and $\mathrm{T}_{50}$ of PVC0 are lower than those of the PVC matrix composites. With increasing of the usage of DOP in modified nano- $\mathrm{Sb}_{2} \mathrm{O}_{3}$, the $\mathrm{T}_{10}$ and $\mathrm{T}_{50}$ of the PVC matrix composites firstly increase and then decrease. Meanwhile, the $\mathrm{T}_{\mathrm{P} 1}$ of the PVC0 is $296.72^{\circ} \mathrm{C}$ and higher than that of the other PVC matrix composites. The phenomenon is due to the presence of nano- $\mathrm{Sb}_{2} \mathrm{O}_{3}$ and DOP of modified nano- $\mathrm{Sb}_{2} \mathrm{O}_{3}$. $\mathrm{Sb}_{2} \mathrm{O}_{3}$, as a metal oxide,

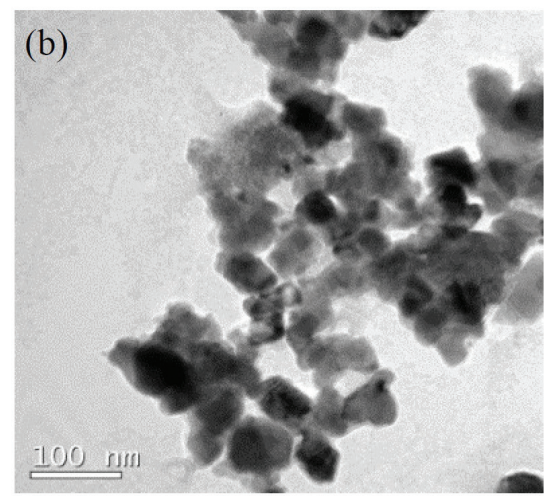

Figure 3. TEM images of the experimental nano- $\mathrm{Sb}_{2} \mathrm{O}_{3}$. (a)unmodified nano- $\mathrm{Sb}_{2} \mathrm{O}_{3}$, (b) nano- $\mathrm{Sb}_{2} \mathrm{O}_{3} @ 5 \mathrm{wt} \% \mathrm{DOP}$. 

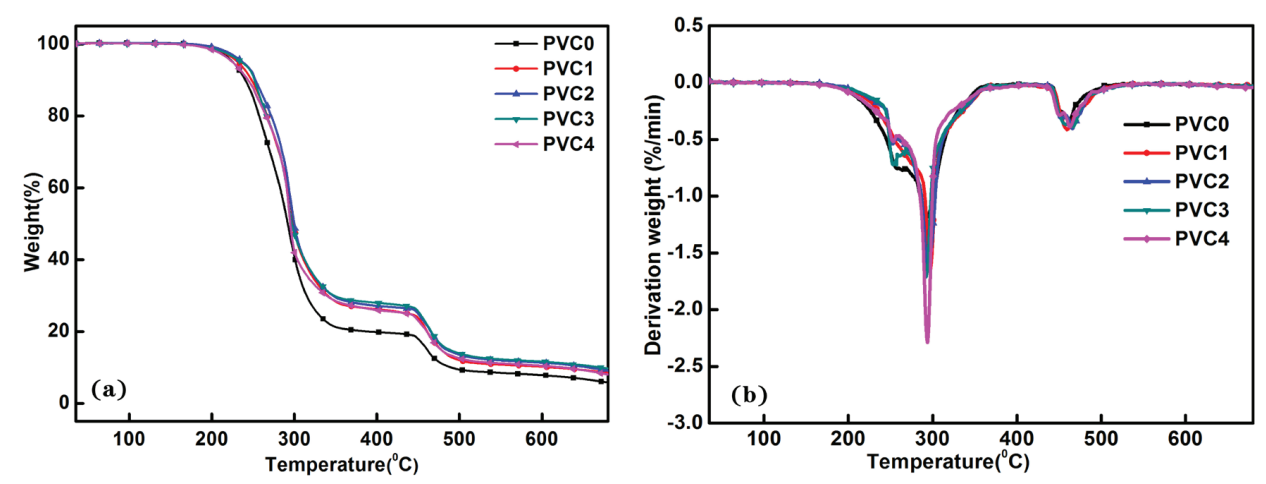

Figure 4. TGA (a) and DTG (b) curves of the experimental materials.

Table 2. Parameters of TGA and DTG of the experimental materials.

\begin{tabular}{ccccccc}
\hline Samples & $\mathrm{T}_{\mathrm{d}}\left({ }^{\circ} \mathrm{C}\right)$ & $\mathrm{T}_{10}\left({ }^{\circ} \mathrm{C}\right)$ & $\mathrm{T}_{50}\left({ }^{\circ} \mathrm{C}\right)$ & $\mathrm{T}_{\mathrm{P} 1}\left({ }^{\circ} \mathrm{C}\right)$ & $\mathrm{T}_{\mathrm{P} 2}\left({ }^{\circ} \mathrm{C}\right)$ & char yield $((\%)$ \\
\hline PVC0 & 197.32 & 240.34 & 292.00 & 296.72 & 463.22 & 5.28 \\
\hline PVC1 & 196.87 & 246.48 & 298.49 & 295.95 & 458.54 & 8.07 \\
\hline PVC2 & 197.10 & 252.84 & 298.49 & 293.30 & 462.99 & 8.44 \\
\hline PVC3 & 194.98 & 252.84 & 298.68 & 292.33 & 464.35 & 9.24 \\
\hline PVC4 & 191.86 & 242.30 & 294.31 & 292.67 & 464.34 & 7.44 \\
\hline
\end{tabular}

also has the catalysis in polymer ${ }^{17}$, namely nano- $\mathrm{Sb}_{2} \mathrm{O}_{3}$ can promote the degradation of DOP and removal of $\mathrm{HCl}$ in $\mathrm{PVC}$.

The second stage of the thermal degradation of the experimental materials occurred in the range of $450 \sim 700{ }^{\circ} \mathrm{C}$. At the stage, the mass loss is mainly caused by the combustion of PVC matrix materials. If the internal structure of PVC is modified to form some larger molecular groups, such as aromatic hydrocarbon or long carbon chain, it can promote its cross-linking of molecular chain and form to charcoal. The PVC3 sample has the highest $\mathrm{T}_{\mathrm{P} 2}$ temperature $\left(464.35^{\circ} \mathrm{C}\right)$ and the highest char residue $(9.24 \%)$, which the two indexes are higher than those of other materials. It indicates that the nano- $\mathrm{Sb}_{2} \mathrm{O}_{3}$ modified by DOP with $5 \mathrm{wt} \%$ of usage can promote the char formation of PVC matrix composites, which can effectively prevent the contact between oxygen and combustion surface to enhance the flame retardancy of the experimental composites.

\subsection{Cone calorimetric measurements}

The combustion characteristics of the experimental materials are evaluated by cone calorimetry, which is one of the most effective methods to evaluate the combustion performance of materials. Figure 5 and Table 3 show the testing curve and relevant data, respectively. The main testing indexes are heat release rate (HRR), total heat release (THR), smoke production rate (SPR), total smoke production (TSP), peak heat release rate (PHRR), peak smoke production rate (PSPR), effective heat combustion (EHC), $\mathrm{CO}$ content ratio $(\mathrm{COR})$ and $\mathrm{CO}_{2}$ content ratio $\left(\mathrm{CO}_{2} \mathrm{R}\right)$ in smoke.

It can be clearly seen that the burning time of the PVC0 sample is significantly longer than that of the other samples. The HRR value of the PVC0 is distinctly higher than that of the other materials, reaching a maximum value (PHRR) of $307.04 \mathrm{kw} / \mathrm{m}^{2}$ at $111 \mathrm{~s}$ of burning time. The PHRR values of the PVC1, PVC2, PVC3 and PVC4 are respectively 247.43,
218.20, 215.96 and $214.95 \mathrm{kw} / \mathrm{m}^{2}$, which is significantly lower than that of the PVC0 sample. Pure PVC (PVC0) releases a lot of heat during combustion, and its THR is higher than those of PVC matrix composites containing nano- $\mathrm{Sb}_{2} \mathrm{O}_{3}$. The THR value of PVC3 is $25.3 \mathrm{MJ} / \mathrm{m}^{2}$, which is the lowest among the experimental PVC matrix composites. Therefore, nano- $\mathrm{Sb}_{2} \mathrm{O}_{3}$ can distinctly reduce the HRR and THR value of the PVC matrix composites.

EHC is the ratio of HRR to mass loss rate, which reflects the combustion degree of polymers. The EHC of PVCO is the highest $(15.7 \mathrm{MJ} / \mathrm{kg})$ and that of PVC3 is the lowest $(10.2 \mathrm{MJ} / \mathrm{kg})$. The results show that the nano- $\mathrm{Sb}_{2} \mathrm{O}_{3}$ modified by DOP with $5 \mathrm{wt} \%$ of usage has the best inhibition effect of heat release on PVC matrix composites.

Observing the smoke production of the experimental materials during combustion testing, it can be found that PVC0 sample produced a large amount of smoke, while the amount of smoke production of the others samples is significantly less than that of PVC0. The PSPR of PVC0 is $0.190 \mathrm{~m}^{2} / \mathrm{s}$ and higher than those of the others samples. In addition, different amounts of DOP to modify nano$\mathrm{Sb}_{2} \mathrm{O}_{3}$ also have disparate effect on the value of SPR of PVC matrix composites. When nano- $\mathrm{Sb}_{2} \mathrm{O}_{3}$ is modified by DOP with 5 wt. $\%$ of mass fraction, the PSPR value of PVC3 decreases to the lowest value, which is $0.114 \mathrm{~m}^{2} / \mathrm{s}$. However, when nano- $\mathrm{Sb}_{2} \mathrm{O}_{3}$ is modified by DOP with $7 \mathrm{wt} . \%$ of mass fraction, the PSPR value of PVC4 rebounds to $0.129 \mathrm{~m}^{2} / \mathrm{s}$. The results show that the nano- $\mathrm{Sb}_{2} \mathrm{O}_{3}$ modified by appropriate amount of DOP can effectively reduce the smoke production of PVC matrix composites.

$\mathrm{COR}$ and $\mathrm{CO}_{2} \mathrm{R}$ are the mass fractions of $\mathrm{CO}$ and $\mathrm{CO}_{2}$ gases released during combustion of experimental materials, respectively. The absolute content of $\mathrm{CO}$ and $\mathrm{CO}_{2}$ is the product of TSP and COR and $\mathrm{CO}_{2} \mathrm{R}$, respectively. For PVC0, COR and $\mathrm{CO}_{2} \mathrm{R}$ are $9.7 \%$ and $82 \%$ and the 

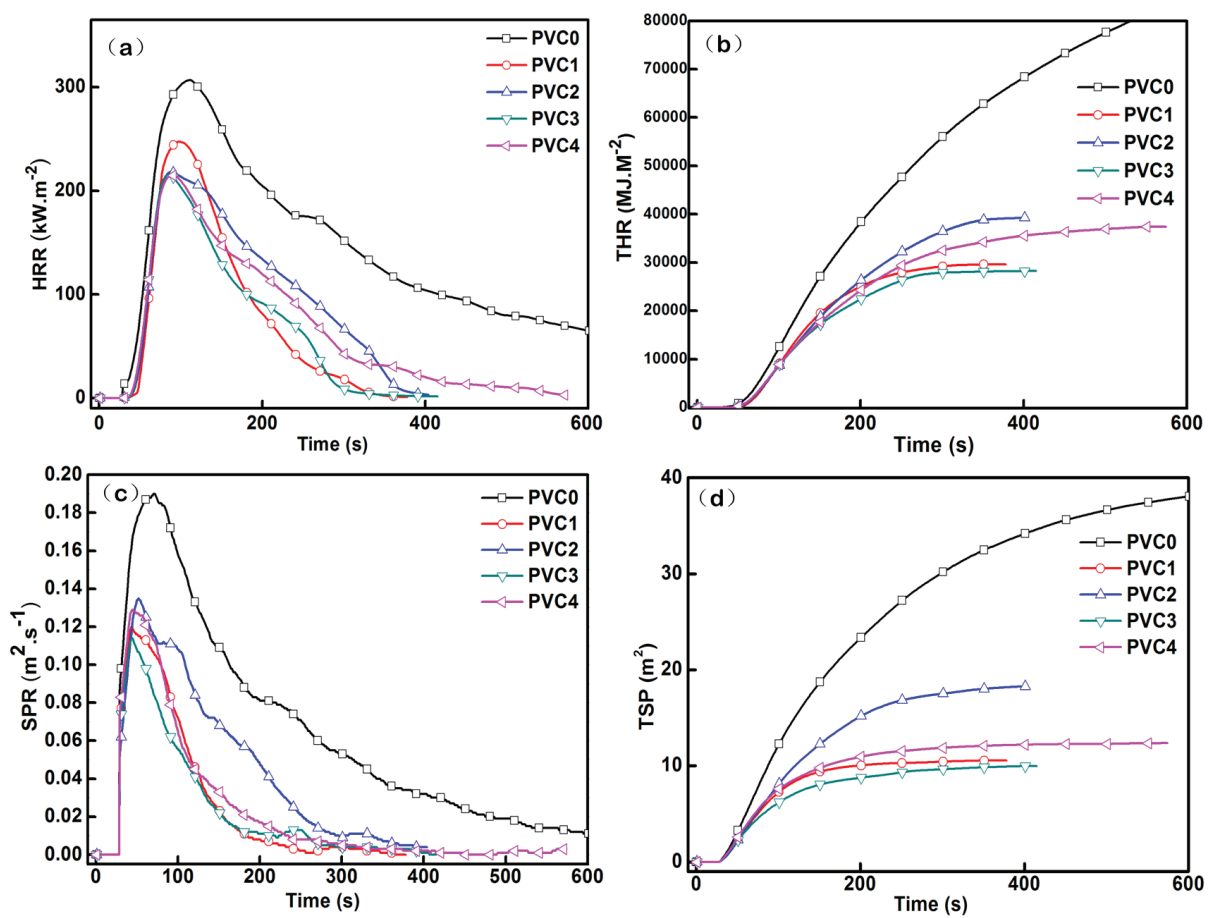

Figure 5. (a) Heat release rate (HRR); (b) total heat release rate (THR); (c) smoke production rate (SPR); (d) total smoke production (TSP) as a function of the burning time for the PVC and its composites in the cone calorimeter tests at $50 \mathrm{kw} / \mathrm{m}^{2}$.

Table 3. Cone calorimeter data of the experimental materials.

\begin{tabular}{cccccccc}
\hline Samples & THR $\left(\mathrm{MJ} / \mathrm{m}^{2}\right)$ & PHRR $\left(\mathrm{kw} / \mathrm{m}^{2}\right)$ & EHC $(\mathrm{MJ} / \mathrm{kg})$ & PSPR $\left(\mathrm{m}^{2} / \mathrm{s}\right)$ & TSP $\left(\mathrm{m}^{2}\right)$ & COR $(\%)$ & $\mathrm{CO}_{2} \mathrm{R}(\%)$ \\
\hline PVC0 & 101.5 & 307.04 & 15.7 & 0.190 & 42.1 & 9.7 & 82 \\
\hline PVC1 & 28.6 & 247.43 & 13.0 & 0.119 & 10.9 & 13.7 & 72 \\
\hline PVC2 & 37.2 & 218.20 & 11.6 & 0.135 & 17.9 & 11.6 & 74 \\
\hline PVC3 & 25.3 & 215.96 & 10.2 & 0.114 & 9.6 & 12.1 & 60 \\
\hline PVC4 & 36.6 & 214.95 & 12.9 & 0.129 & 12.9 & 10.3 & 77 \\
\hline
\end{tabular}

absolute content of $\mathrm{CO}$ and $\mathrm{CO}_{2}$ are $4.084 \mathrm{~m}^{2}$ and $34.522 \mathrm{~m}^{2}$, respectively. It can be seen that PVC0 not only produces a lot of smoke, but also produces more $\mathrm{CO}$ and $\mathrm{CO}_{2}$, which the total mass fraction is $91.7 \%$. For the experimental composites, their COR is higher than that of $\mathrm{PVC} 0$ and $\mathrm{CO}_{2} \mathrm{R}$ is lower than that of PVC0. However, the absolute content of $\mathrm{CO}$ and $\mathrm{CO}_{2}$ of the experimental composites are lower than those of PVC0. The absolute contents of $\mathrm{CO}$ of PVC1, PVC2, PVC3 and PVC4 are $1.493 \mathrm{~m}^{2}, 2.0764 \mathrm{~m}^{2}$, $1.162 \mathrm{~m}^{2}$ and $1.329 \mathrm{~m}^{2}$, respectively. And the absolute contents of $\mathrm{CO}_{2}$ of $\mathrm{PVC} 1, \mathrm{PVC} 2, \mathrm{PVC} 3$ and PVC4 are $7.848 \mathrm{~m}^{2}$, $13.246 \mathrm{~m}^{2}, 5.76 \mathrm{~m}^{2}$ and $9.933 \mathrm{~m}^{2}$, respectively. Among the experimental materials, $\mathrm{PVC} 3$ has the minimum absolute contents of $\mathrm{CO}$ and $\mathrm{CO}_{2}$. The above test results show that nano- $\mathrm{Sb}_{2} \mathrm{O}_{3}$ can effectively reduce the absolute contents of $\mathrm{CO}$ and $\mathrm{CO}_{2}$. Moreover, nano- $\mathrm{Sb}_{2} \mathrm{O}_{3}$ can react with $\mathrm{HCl}$ to form $\mathrm{SbCl}_{3}$ during combustion. The $\mathrm{SbCl}_{3}$ can hinder the contact of oxygen and burning surface, resulting in COR of $\mathrm{PVC}$ matrix composites increases and their $\mathrm{CO}_{2} \mathrm{R}$ decreases. However, due to the better flame retardant effect of nano$\mathrm{Sb}_{2} \mathrm{O}_{3}$, TSP of the composites during combustion reduces, resulting in the absolute content of $\mathrm{CO}$ and $\mathrm{CO}_{2}$ decrease. Finally, the nano- $\mathrm{Sb}_{2} \mathrm{O}_{3}$ modified by DOP with $5 \mathrm{wt} \%$ of usage has better dispersibility in PVC matrix material. The nano- $\mathrm{Sb}_{2} \mathrm{O}_{3}$ with better dispersibility is more helpful to improve the flame retardancy of the composites, resulting in the minimum absolute contents of $\mathrm{CO}$ and $\mathrm{CO}_{2}$ of PVC3.

Figure 6 shows morphology photographs of the char residuals of experimental materials tested by cone calorimeter testing. It can be seen from the figure that the surface of PVC0 hardly forms a dense carbon layer, while the surfaces of the PVC matrix composites containing nano- $\mathrm{Sb}_{2} \mathrm{O}_{3}$ form a carbon layer. The surface carbon layer of PVC3 is the densest among the PVC matrix composites. These carbon layers can effectively inhibit the heat transfer and isolate the oxygen in the air. The denser the carbon layer is, the better the barrier effect is.

In order to observe the microstructure in detail, SEM images of the char residuals of the experimental composites are presented in Figure 7. It can be seen from the figure that the burning surface of the PVC1 has some large pores, which indicates the flame retarding efficiency is lower basing 

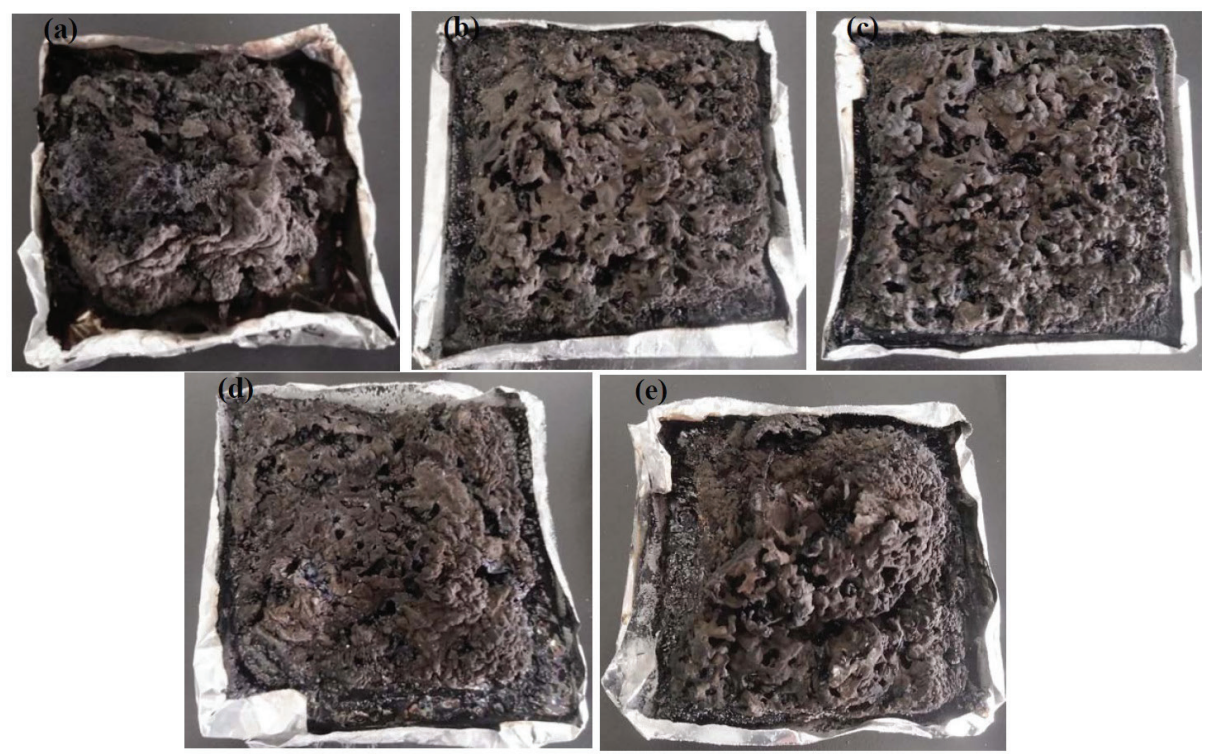

Figure 6. Morphology photographs of the char residuals of experimental materials tested by cone calorimeter testing. (a) PVC0, (b) PVC1, (c) PVC2, (d) PVC3, (e) PVC4.
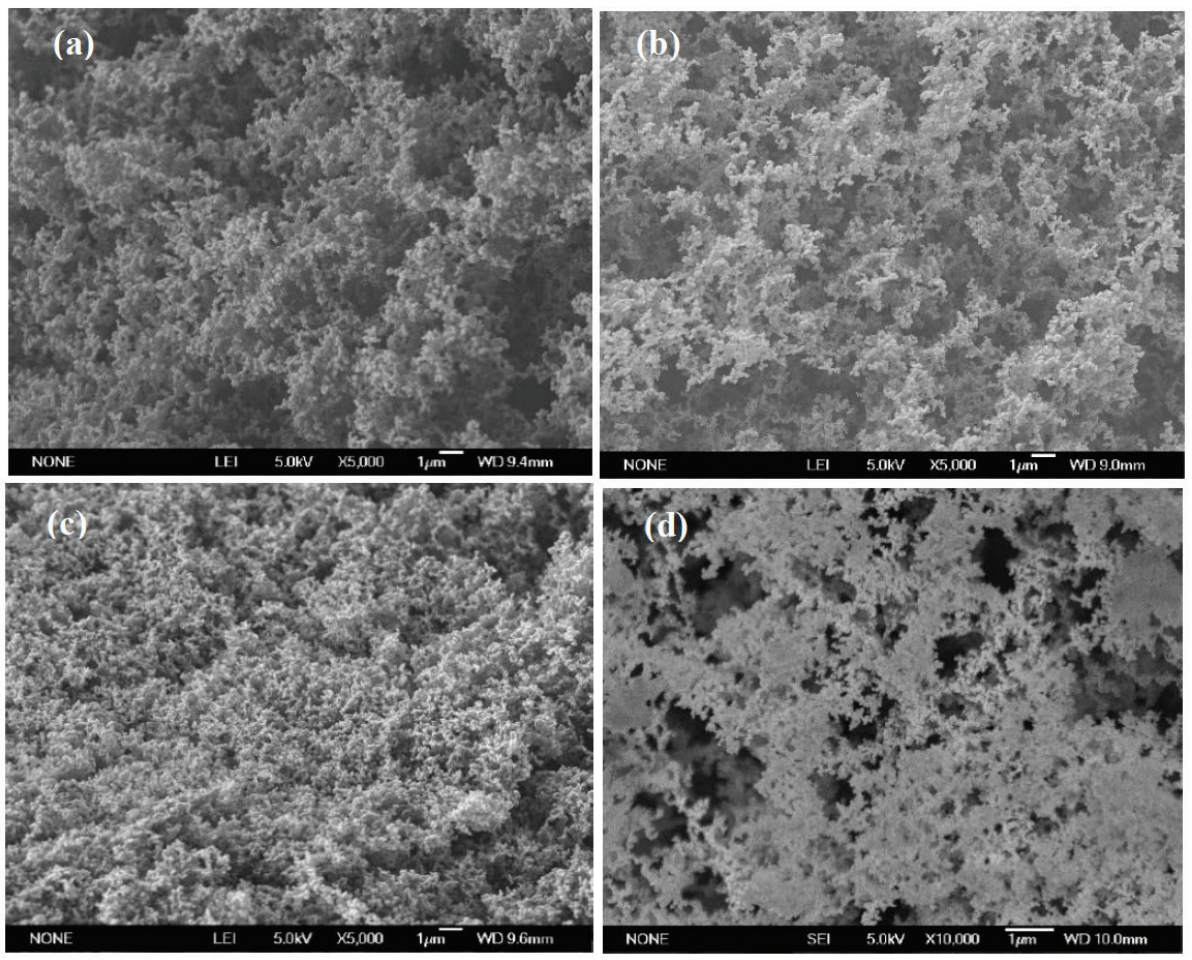

Figure 7. SEM images of the char residuals of the experimental composites. (a) PVC1, (b) PVC2, (c) PVC3, (d) PVC4.

on solid phase flame retardant mechanism. The relative density of residual carbon of the samples is different when nano- $\mathrm{Sb}_{2} \mathrm{O}_{3}$ modified by DOP with different usage is used. The dense carbon layer can effectively improve the flame retardancy of the composites. Using nano- $\mathrm{Sb}_{2} \mathrm{O}_{3}$ modified by DOP with $5 \mathrm{wt} \%$ of usage as additive, a dense carbon layer is formed on the combustion surface of $\mathrm{PVC} 3$ because of the better dispersibility of nano- $\mathrm{Sb}_{2} \mathrm{O}_{3}$ in PVC matrix, which can promote the flame retardancy efficiency and the char formation of the composites.

\subsection{Flammability}

The flame retardancy of the experimental materials is characterized by LOI and UL-94 grade and these results are listed in Table 4. In UL94 testing, PVC0 sample is flammable accompany with serious melt-dripping phenomenon and its 
UL94 grade is HB level, which indicates that it has a greater fire risk. For PVC1, PVC2, PVC3, and PVC4 samples, there is no melt-dripping phenomenon in the combustion processing of the samples, and the combustion time is shortened. PVC3 sample has the shortest combustion time and reaches $\mathrm{V}-0$ level of UL94 grade. In LOI testing, the LOI value of PVC0 is $20.3 \%$, which is significantly lower than those of the experimental composites. With the increasing of the usage of DOP to modified nano- $\mathrm{Sb}_{2} \mathrm{O}_{3}$, the LOI value of PVC matrix composites samples increases firstly and then decreases. When the usage of DOP is $5 \mathrm{wt} \%$, the LOI value of PVC3 sample reaches the maximum of $29.8 \%$. These results indicated that the nano- $\mathrm{Sb}_{2} \mathrm{O}_{3}$ modified by DOP has better flame retardant efficiency, especially nano$\mathrm{Sb}_{2} \mathrm{O}_{3}$ modified by DOP with $5 \mathrm{wt} \%$ of usage has the best flame retardant effect.

Figure 8 shows the original photos and the UL94 testing completing photos of the experimental materials. In the

Table 4. LOI and UL94 gradeof the experimental materials.

\begin{tabular}{cccc}
\hline \multirow{2}{*}{ Samples } & \multirow{2}{*}{ LOI(\%) } & \multicolumn{2}{c}{ UL94 } \\
\cline { 3 - 4 } & & Dripping & Grade \\
\hline PVC0 & $20.3 \pm 1$ & Yes & HB \\
\hline PVC1 & $29.1 \pm 1$ & No & V-1 \\
\hline PVC2 & $29.7 \pm 1$ & No & V-0 \\
\hline PVC3 & $29.8 \pm 1$ & No & V-0 \\
\hline PVC4 & $29.4 \pm 1$ & No & V-1 \\
\hline
\end{tabular}

Table 5. Tensile properties of the experimental materials.

\begin{tabular}{ccc}
\hline Samples & $\begin{array}{c}\text { Tensile strength } \\
(\mathrm{MPa})\end{array}$ & $\begin{array}{c}\text { Young's modulus } \\
(\mathrm{GPa})\end{array}$ \\
\hline PVC0 & $13.5 \pm 0.5$ & $1.6 \pm 0.1$ \\
\hline PVC1 & $12.7 \pm 0.7$ & $1.4 \pm 0.1$ \\
\hline PVC2 & $13.7 \pm 0.7$ & $1.7 \pm 0.1$ \\
\hline PVC3 & $15.9 \pm 0.9$ & $2.1 \pm 0.1$ \\
\hline PVC4 & $13.4 \pm 0.7$ & $1.7 \pm 0.1$ \\
\hline
\end{tabular}

UL94 testing, PVC0 sample is severely burned and almost no dense carbon layer formed on the surface. Compared with PVC0, the burning loss of the experimental composites is not very serious, which attributes to flame retardant synergism of nano- $\mathrm{Sb}_{2} \mathrm{O}_{3}$. PVC3 has the smallest burning loss and a compact carbon layer on the burning surface compared with other composite materials. This shows that PVC3 has the best flame retardant performance, which is consistent with the results of cone calorimetry.

\subsection{Tensile properties}

Table 5 shows the tensile properties of the experimental materials. It can be seen from the Table 5 that the tensile strength of pure PVC is $13.5 \mathrm{MPa}$ and its Young's modulus is $1.6 \mathrm{GPa}$. The tensile strength and Young's modulus of PVC1 are lower than those of PVC0. With increasing of usage of DOP to modify nano- $\mathrm{Sb}_{2} \mathrm{O}_{3}$, the tensile strength and Young's modulus of PVC matrix composites increase firstly and then decrease. When the usage of DOP is $5 \mathrm{wt} \%$, the tensile strength and Young's modulus of the composites (PVC3 sample) reach the maximum value, which are $15.9 \mathrm{MPa}$ and $2.1 \mathrm{GPa}$, respectively. As is well known, the main problem to be solved is the agglomeration of nanoparticles when nanoparticles additives are added into polymers. The unmodified nano- $\mathrm{Sb}_{2} \mathrm{O}_{3}$ nanoparticles easily agglomerate in PVC matrix, such as PVC1. A large amount of unmodified nano- $\mathrm{Sb}_{2} \mathrm{O}_{3}$ aggregates will produce a splitting effect when the composites is subjected to tensile force. Therefore, the tensile strength and Young's modulus of PVC1 seriously decreases. When the surface of nano- $\mathrm{Sb}_{2} \mathrm{O}_{3}$ nanoparticles is modified by DOP $(\leq 5 \mathrm{wt} \%)$, it can effectively solve the agglomeration problem of the nanoparticles in PVC matrix, and nano- $\mathrm{Sb}_{2} \mathrm{O}_{3}$ nanoparticles have better dispersion and interface compatibility with PVC matrix. Under the tensile force for PVC matrix composites, the well dispersed nano$\mathrm{Sb}_{2} \mathrm{O}_{3}$ particles can prevent the extension of tensile crack and improve the tensile strength and Young's modulus. However, when the usage of DOP to modified nano- $\mathrm{Sb}_{2} \mathrm{O}_{3}$ is too high

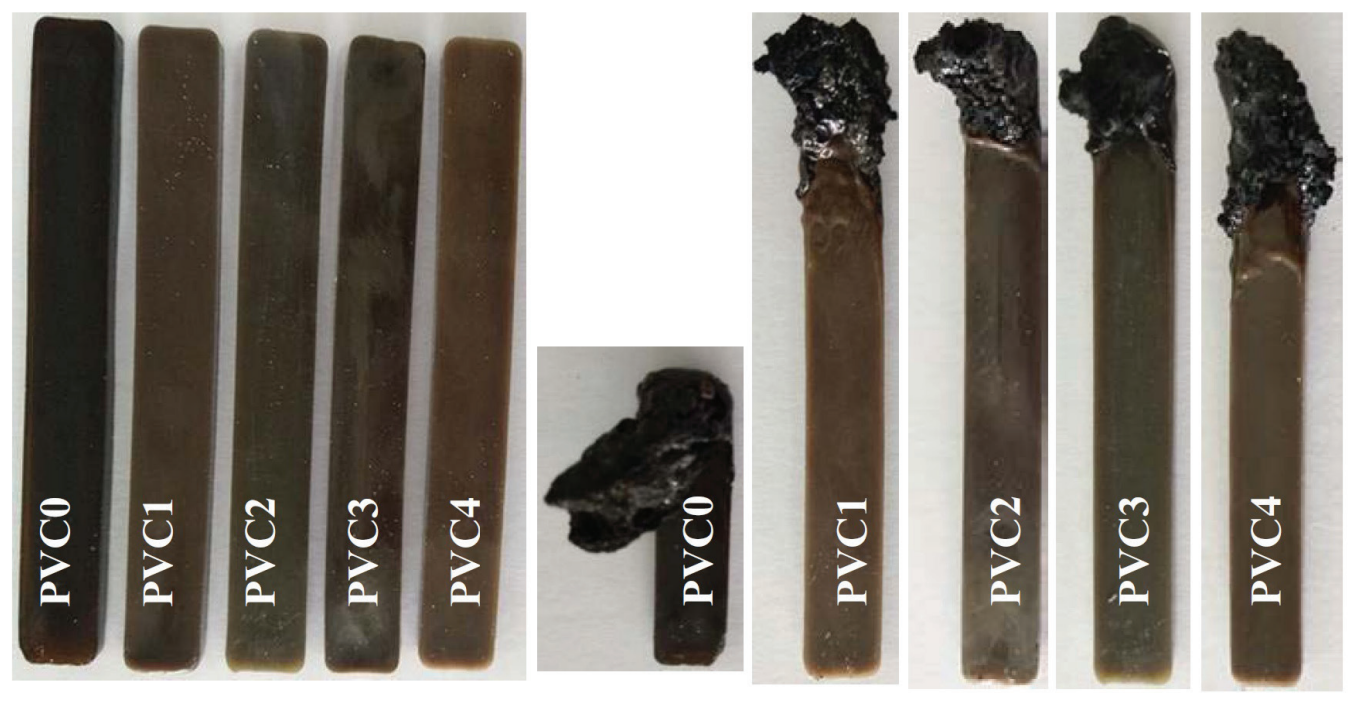

Figure 8. The original photos and the UL94 testing completing photos of the experimental materials. 
( $>5 \mathrm{wt} \%$ ), the tensile strength and Young's modulus of the PVC matrix composites (PVC4 sample) were negatively affected due to the soft nature of DOP. Therefore, the tensile strength and Young's modulus of the PVC4 would decrease again ${ }^{19}$.

Figure 9 shows SEM images of tensile fracture of PVC0 and PVC3 samples. It can be seen from Figure 9(a) that the particle size of unmodified $\mathrm{Sb}_{2} \mathrm{O}_{3}$ is larger with serious agglomeration phenomenon in PVC matrix material. The dispersibility of nano- $\mathrm{Sb}_{2} \mathrm{O}_{3}$ modified by DOP with $5 \mathrm{wt} \%$ of usage is significantly improved and the particle size reduced in PVC3, as shown in Figure 9(b). When the composites are subjected to tensile force, the smaller the particle size of the nanoparticles is, the cracking effect of the nanoparticles on the matrix material will be restrained. Therefore, the tensile strength and elongation of the composites are improved.

\subsection{Discussion on flame retardant and modification mechanism of nano- $\mathrm{Sb}_{2} \mathrm{O}_{3}$}

The combustion reaction of PVC matrix composites can be divided into two steps. The first step is the decomposing of DOP and volatilizing of $\mathrm{HCl}$ in PVC matrix ${ }^{17,20}$. The second step is the flame retardant reaction. The main chemical reactions of nano- $\mathrm{Sb}_{2} \mathrm{O}_{3}$ in $\mathrm{PVC}$ matrix composites in the step are as follows:

$$
\begin{aligned}
& \mathrm{Sb}_{2} \mathrm{O}_{3}(\mathrm{~s})+2 \mathrm{HCl}(\mathrm{g}) \stackrel{205^{\circ} \mathrm{C}}{\longrightarrow} 2 \mathrm{SbOCl}^{(\mathrm{s})}+\mathrm{H}_{2} \mathrm{O}(\mathrm{g}) \\
& \mathrm{Sb}_{2} \mathrm{O}_{3}(\mathrm{~s})+6 \mathrm{HCl}(\mathrm{g}) \stackrel{205^{\circ} \mathrm{C}}{\longrightarrow} 2 \mathrm{SbCl}_{3}(\mathrm{~g})+3 \mathrm{H}_{2} \mathrm{O}(\mathrm{g}) \\
& 5 \mathrm{SbOCl}(\mathrm{s}) \stackrel{245-280^{\circ} \mathrm{C}}{\longrightarrow} \mathrm{Sb}_{4} \mathrm{O}_{5} \mathrm{Cl}_{2}(\mathrm{~s})+\mathrm{SbCl}_{3}(\mathrm{~g}) \\
& 4 \mathrm{Sb}_{4} \mathrm{O}_{5} \mathrm{Cl}_{2}(\mathrm{~s}) \stackrel{245-475^{\circ} \mathrm{C}}{\longrightarrow} 5 \mathrm{Sb}_{3} \mathrm{O}_{4} \mathrm{Cl}(\mathrm{s})+\mathrm{SbCl}_{3}(\mathrm{~g}) \\
& 3 \mathrm{Sb}_{3} \mathrm{O}_{4} \mathrm{Cl}(\mathrm{s}) \stackrel{245-565^{\circ} \mathrm{C}}{\longrightarrow} 4 \mathrm{Sb}_{2} \mathrm{O}_{3}(\mathrm{~s})+\mathrm{SbCl}_{3}(\mathrm{~g})
\end{aligned}
$$

The resulting $\mathrm{SbCl}_{3}(\mathrm{~g})$ with a boiling point of $233^{\circ} \mathrm{C}$ is gasified under high temperature in the combustion zone, which can dilute the concentration of oxygen and act as a diluent to play a certain role in flame retardancy. In addition, nano- $\mathrm{Sb}_{2} \mathrm{O}_{3}$ can capture a lot of active hydrogen ions and absorb a lot of reaction heat during the flame retardant reaction process, which can greatly prevent the combustion reaction and flame spread of the matrix material ${ }^{1}$.

Figure 10 illustrates the mechanism of nano- $\mathrm{Sb}_{2} \mathrm{O}_{3}$ modified by DOP. The nano- $\mathrm{Sb}_{2} \mathrm{O}_{3}$ particles in the paper are prepared by wet grinding method of high energy ball mill basing on micro- $\mathrm{Sb}_{2} \mathrm{O}_{3}$ particles as raw materials. A lot of hydroxyl groups $(-\mathrm{OH})$ are produced on the surface of nano- $\mathrm{Sb}_{2} \mathrm{O}_{3}$ due to the effect of high energy ball milling ${ }^{14,21}$. Nano- $\mathrm{Sb}_{2} \mathrm{O}_{3}$ particles take place agglomeration under the action of hydrogen bond between hydroxyl groups. The tensile properties and flame retardant of the PVC matrix composites will be deteriorated when the nano- $\mathrm{Sb}_{2} \mathrm{O}_{3}$ particles agglomerate in PVC matrix, which is consistent with the experimental results of PVC1 sample. During combustion process, the agglomerated nano- $\mathrm{Sb}_{2} \mathrm{O}_{3}$ particles can not fully participate in the flame retardant reaction. It not only worsens the meteorological flame retardant effect because of the reducing of the amount of resulting $\mathrm{SbCl}_{3}$, but also reduces the ability to absorb the reaction heat. Meanwhile, the dilution effect of $\mathrm{SbCl}_{3}$ is decreased due to the decreasing of the amount of $\mathrm{SbCl}_{3}$. Therefore, PVC1 not only has lower thermal stability, but also has lower carbon residual rate anddensity of carbon layer. When DOP is used to modify the surface of nano- $\mathrm{Sb}_{2} \mathrm{O}_{3}$ particles, the hydrogen ions of DOP molecular chain can combine with the hydroxyl groups on the surface of nano- $\mathrm{Sb}_{2} \mathrm{O}_{3}$ particles, resulting in making DOP coated on the surface of nano$\mathrm{Sb}_{2} \mathrm{O}_{3}$ particles ${ }^{13}$. The modified nano- $\mathrm{Sb}_{2} \mathrm{O}_{3}$ can greatly reduce the surface hydrogen bonding effect and improve its dispersibility in PVC matrix. Meanwhile, the modified nano$\mathrm{Sb}_{2} \mathrm{O}_{3}$ has good interface compatibility with PVC matrix. With increasing of DOP usage, the modification effect of nano- $\mathrm{Sb}_{2} \mathrm{O}_{3}$ becomes better. Therefore, when the DOP usage reaches $5 \mathrm{wt} \%$, the PVC matrix composites (PVC3 sample) has good tensile strength and flame retardancy, which is due to the good interfacial compatibility and dispersibility of nano- $\mathrm{Sb}_{2} \mathrm{O}_{3}$ particles. The nano- $\mathrm{Sb}_{2} \mathrm{O}_{3}$ particles with good dispersibility can participate sufficiently in the flame retardant reaction to produce a large amount of $\mathrm{SbCl}_{3}$ and absorb a large amount of heat to form a dense carbon layer. Thus, the thermal stability of PVC matrix composites is increased accompanying with higher char yield. When the usage of DOP is more than $5 \mathrm{wt} \%$, the excess DOP decreases LOI and
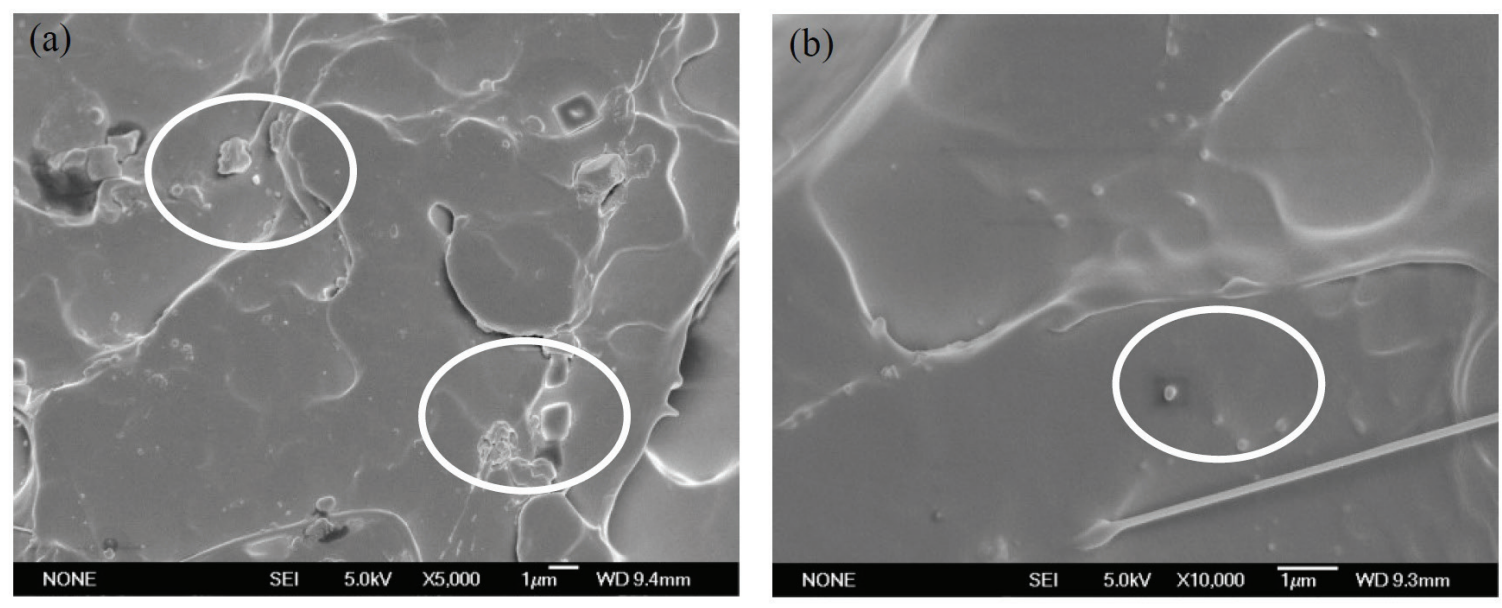

Figure 9. SEM images of tensile fracture of PVC0 and PVC3 samples; (a) PVC1, (b) PVC3. 

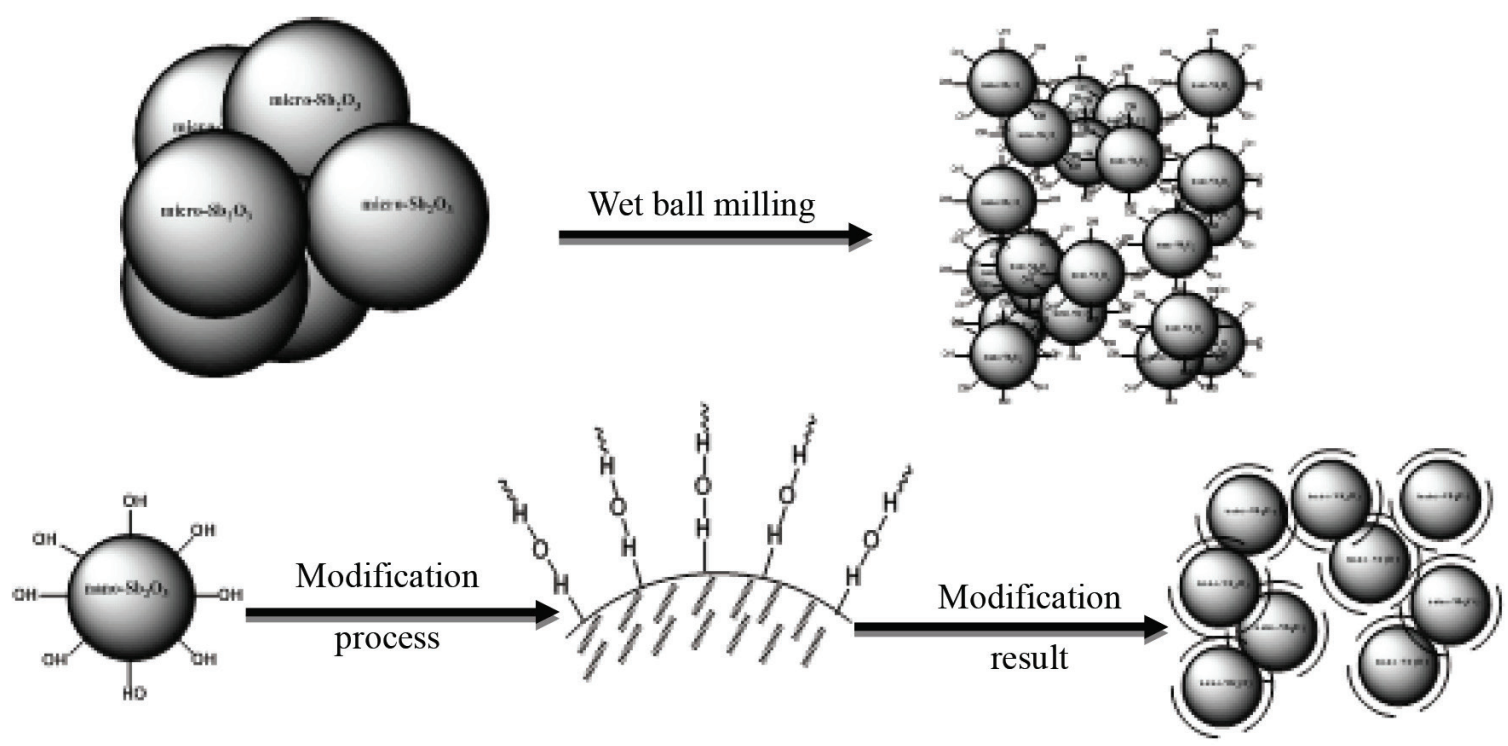

Figure 10. The schematic of the modification of nano- $\mathrm{Sb}_{2} \mathrm{O}_{3}$ particles.

UL94 grade of PVC matrix composites, and at the same time reduce the tensile strength of the composites because of the soft nature of DOP. Therefore, although DOP does not have flame retardancy, appropriate DOP can indirectly improve the flame retardancy and tensile strength of nano- $\mathrm{Sb}_{2} \mathrm{O}_{3} / \mathrm{DOP} /$ PVC composites basing on improving the dispersibility and interfacial compatibility of nano- $\mathrm{Sb}_{2} \mathrm{O}_{3}$ in the composites.

\section{Conclusions}

Using dioctyl phthalate (DOP) as modifier, antimony trioxide nanoparticles (nano- $\mathrm{Sb}_{2} \mathrm{O}_{3}$ ) as flame retardant additives and polyvinyl chloride (PVC) as matrix material, nano- $\mathrm{Sb}_{2} \mathrm{O}_{3} / \mathrm{DOP} / \mathrm{PVC}$ composites with better flame retardancy, thermal stability and tensile strength were prepared and characterized. Some conclusions are drawn from the study and are as follows:

1. Nano- $\mathrm{Sb}_{2} \mathrm{O}_{3}$ particles modified by appropriate DOP can improve the thermal stability and char yield of PVC matrix composites. The PVC matrix composites containing $2 \mathrm{wt} \%$ nano- $\mathrm{Sb}_{2} \mathrm{O}_{3}$ particles modified by DOP with $5 \mathrm{wt} \%$ of usage has better thermal stability and higher char yield of $9.24 \%$.

2. Modified nano- $\mathrm{Sb}_{2} \mathrm{O}_{3}$ particles modified by appropriate DOP can improve flame retardancy of PVC matrix composites because the nano- $\mathrm{Sb}_{2} \mathrm{O}_{3}$ particles with good dispersibility can participate sufficiently in the flame retardant reaction, absorb a large amount of reaction heat and promote the formation of dense carbon layer. The PVC matrix composites containing $2 \mathrm{wt} \%$ nano- $\mathrm{Sb}_{2} \mathrm{O}_{3}$ particles modified by DOP with $5 \mathrm{wt} \%$ of usage has excellent flame retardancy, which its LOI is $29.8 \%$ and UL94 grade is V-0 level. Meanwhile, the heat release rate (HRR), smoke production rate (SPR), effective heat combustion (EHC), $\mathrm{CO}$ content ratio (COR) and $\mathrm{CO}_{2}$ content ratio $\left(\mathrm{CO}_{2} \mathrm{R}\right)$ of the PVC matrix composites with $2 \mathrm{wt} \%$ nano- $\mathrm{Sb}_{2} \mathrm{O}_{3}$ modified by DOP with $5 \mathrm{wt} \%$ of usage is significantly reduced.

3. Nano- $\mathrm{Sb}_{2} \mathrm{O}_{3}$ particles modified by appropriate DOP can improve tensile strength of PVC matrix composites due to good dispersibility and interface compatibility of nano- $\mathrm{Sb}_{2} \mathrm{O}_{3}$ particles in PVC matrix. Using $2 \mathrm{wt} \%$ nano- $\mathrm{Sb}_{2} \mathrm{O}_{3}$ particles modified by DOP with $5 \mathrm{wt} \%$ of usage as flame retardant additives, the tensile strength and Young's modulus of the nano- $\mathrm{Sb}_{2} \mathrm{O}_{3} / \mathrm{DOP} / \mathrm{PVC}$ composites are $15.9 \mathrm{MPa}$ and $2.1 \mathrm{GPa}$, respectively.

\section{Acknowledgments}

The work was supported by the National Natural Science Foundation of China (No. 51761025).

\section{References}

1. Xu JL, Zhou SG, Niu L, Feng C, Yang WL, Dan XM. Preparation and flame retardancy of $\mathrm{Sb}_{2} \mathrm{O}_{3}$ /polyvinyl chloride composites. Journal of Materials Heat Treatment. 2015;36(11):1-6.

2. Xie W, Zeng X. Research progress on flame retardant and smoke suppression of polyvinyl chloride. Plastics Additives. 2017;(6):5-9,24.

3. Sun JH. Research progress on flame retardant and smoke suppressant of polyvinyl chloride transition metal compound. Science \& Technology Vision. 2017;5:194-5.

4. Tian CM, Ye X, Qu HQ, Wu WH, Xie JX, Shi JB, et al. Influence of $\mathrm{Al}(\mathrm{OH})_{3}$ and $\mathrm{Mg}(\mathrm{OH})_{2}$ on flexible $\mathrm{PVC}$ as flame retardants and smoke suppressants. Journal of Hebei University. 2004;24(3):263-7.

5. Wang $\mathrm{CB}$, $\mathrm{Li} \mathrm{B}$. The effect of $\mathrm{Cu}_{2} \mathrm{O}$ and $\mathrm{MoO}_{3}$ on flame retardance and smoke suppression of poly(vinyl chloride). Chemistry and Adhesion. 2002;3:120-6.

6. Sun YL, Zhao BD. Research summary of flame retardant properties of soft PVC. China Rubber/Plastics Technology and Equipment (Plastics). 2016;42(2):14-9.

7. Xie F, Wang YZ, Yang B, Liu Y. A novel intumescent flame-retardant polyethylene system. Macromol Mater Eng. 2006;291(3):247-53. 
8. Zhang S, Horrocks AR. A review of flame retardant polypropylene fibres. Prog Polym Sci. 2003;28(11):1517-38.

9. Si MM, Hao JW, Xu LS, Du JX. Analysis of nano- $\mathrm{Sb}_{2} \mathrm{O}_{3}$ in flame retardancy applications. China Plastics. 2013;27(8):1-7.

10. Porter D, Metcalfe E, Thomas MJK. Nanocomposite fire retardants a review. Fire Mater. 2000;24(1):45-52.

11. Huang GB, Song PG, Liu LN, Han DM, Ge CH, Li RR, et al. Fabrication of multifunctional graphene decorated with bromine andnano-nano- $\mathrm{Sb}_{2} \mathrm{O}_{3}$ towards high-performance polymer nanocomposites. Carbon. 2016;98:689-701.

12. Yang W, Xu J, Niu L, Kang C, Ma B. Analysis of agglomeration and interfacial properties in $\mathrm{PBT} /$ nano- $\mathrm{Sb}_{2} \mathrm{O}_{3}$ composites. $\mathrm{J}$ Adhes Sci Technol. 2018;32(7):739-52.

13. $\mathrm{Xu}$ J, Xu C, Niu L, Kang C. Surface modification of $\mathrm{Sb}_{2} \mathrm{O}_{3}$ nanoparticles with dioctylphthalate. Appl Surf Sci. 2019;485:35-40.

14. Xu JL, Yang WL, Niu L, Dan XM, Wang CC, Wen C. Study on the surface modification of $\mathrm{Sb}_{2} \mathrm{O}_{3}$ nanoparticles by using mechanochemical method. Inorg. Nano-Met. Chem. 2016;47(5):697-702.

15. BSI Standards Publication. BS ISO 5660-1:2015 standard: reaction-to-fire test-heat release, smoke production and mass loss rate. BSI Standards Publication: London, UK: BSI Standards Publication; 2015.
16. Standardization Administration of the People's Republic of China - SAC. GB/T 2406.2-2009: plastics -determination of burning behaviour by oxygen index-part 2: ambient-temperature test. Beijing, China: Standardization Administration of the People's Republic of China; 2009.

17. Jordan KJ, Suib SL, Koberstein JT. Determination of the degradation mechanism from the kinetic parameters of dehydrochlorinated poly(vinyl chloride) decomposition. J Phys Chem B. 2001;105(1):3174-81.

18. Yu J, Sun LS, Ma C, Qiao Y, Yao H. Thermal degradation of PVC: a review. Waste Manag. 2016;48:300-14.

19. Zhou YW, Xiao Y, Li XH, Wang B. Effects of nano-particles on DOP migration and tensile properties of flexible PVC sheets. Adv Mat Res. 2012;548:119-22.

20. Koretsky CM, Sverjensky DA, Salisbury JW, D'aria DM. Detection of surface hydroxyl species on quartz, $\gamma$-alumina, and feldspars using diffuse reflectance infrared spectroscopy. Geochim Cosmochim Acta. 1997;61(11):2193-210.

21. Hotta Y, Yilmaz H, Shirai T, Ohota K, Sato K, Watari K. State of the dispersant and particle surface during wet-jet milling for preparation of a stable slurry. J Am Ceram Soc. 2008;91(4):1095101. 